\title{
ÜPMY tabanlı kafes yapılarının SLE yöntemi ile üretiminde boyut hassasiyetinin incelenmesi
}

\section{Investigation of dimensional accuracy in the production of TPMS-based lattice structures by SLM method}

\author{
Erkan Bahçe ${ }^{1}$ (D), Ender Emir ${ }^{2, *(D)}$, Mehmet Sami Güler ${ }^{3}$ (iD) \\ ${ }^{1}$ İn̈̈nü Üniversitesi, Makine Mühendisliği Bölümü, 44200, Malatya, Türkiye \\ ${ }^{2}$ İstiklal Üniversitesi, Otomotiv Teknolojisi Programı, 46000, Kahramanmaras, Türkive \\ ${ }^{3}$ Ordu Üniversitesi, Makine ve Metal Teknolojileri Programı, 52000, Ordu, Türkiye
}

$\ddot{O} z$

$\mathrm{Bu}$ çalışmada $\mathrm{CoCr}$ tozundan üretilen üçlü periyodik minimum yüzey (ÜPMY) tabanlı kafes yapılarının seçmeli lazer ergitme (SLE) yöntemi ile üretimindeki boyutsal hassasiyetin incelenmesi amaçlanmıştır. İlkel kafes ve hacim merkezli kübik (HMK) olmak üzere $4 \times 4 \times 4$ birim hücre boyutlarında \%10 nispi yoğunluklu 2 farklı ÜPMY kafes yapıs1 kullanıldı. Üretim sonras1 boyutsal hassasiyetin değerlendirilebilmesi için her bir numuneden mikroskop ve micro-CT görüntüleri alınmış ve sonlu elemanlar analizi (SEA) ile üretim simüle edilmiştir. Elde edilen sonuçlarda SLE yöntemi ile ÜPMY bazlı kafes yapılarının üretiminde kütle birikimi, merdiven etkisi ve yapışmış partikül oluşumundan kaynaklı belirgin boyutsal sapmaların meydana geldiği görülmüştür. Tasarlanan kafes yapısı boyutları ile üretim sonucu elde edilen boyutlar incelendiğinde her bir birim kafes yapısının kalınlık değerinin ilkel kafes için \%15, HMK kafes için \%32 saptı̆̆ı, genişlik değerinde ise ilkel kafesin \%4, HMK kafesin ise \%27 saptı̆̆ ve son olarak uzunluk değerlerinde ise ilkel kafesin \%3, HMK kafesin ise $\% 55$ saptı̆̆ tespit edilmiştir.

Anahtar kelimeler: Eklemeli imalat, Seçmeli lazer ergitme, ÜPMY kafes yapıs1, Boyut hassasiyeti

\section{Giris}

Kafes yapıları; yüksek özgül mukavemet, sertlik, iyi ısı yalıtımı ve enerji absorbe edebilme yeteneği sayesinde günümüzde havac1lık, otomotiv, uzay, biyomedikal gibi ürün çıktısı fazla ve maliyetli olan alanlarda tercih edilmektedir [1-6]. 3 boyutlu olarak tasarlanan bu kafes yapıları destek tabanl1, voroni tabanl, ÜPMY ve topoloji optimizasyon tabanlı olmak üzere 4 gruba ayrılmaktadır [7]. Ancak kafes yapılarının gözenek boyutları ve geometrilerinin çok karmaşı olmasından dolayı üretimlerinde problemler ortaya çıkmaktadır. Özellikle geleneksel imalat yöntemlerinin kafes yapılarının üretiminde yetersiz kalması ile birlikte daha hassas ve hızlı bir üretim yöntemi olan eklemeli imalat (Eİ) yöntemi kullanılmaktadır. Kendi içerisinde 7 gruba ayrılan

\section{Abstract}

In this study, it was aimed to examine the geometric precision of the production of triple periodic minimal surface (TPMS) based lattice structures produced from CoCr powder by SLM method. Two different TPMS lattice structures with $10 \%$ relative density of $4 \times 4 \times 4$ unit cell sizes, primitive lattice and body centred cubic (BCC), were used. In order to evaluate the dimensional accuracy after production, microscope images and micro-CT were taken from each sample and production was simulated by finite element analysis (FEA). In the results obtained, it was observed that there were significant dimensional deviations due to mass agglomeration, stair effect and bonded particle formation in the production of TPMS-based lattice structures by SLM method. When the dimensions of the designed lattice structure and the dimensions obtained as a result of production are examined, it is seen that the thickness value of each unit lattice structure deviates by $15 \%$ for the primitive lattice and $32 \%$ for the BCC lattice, while the primitive lattice deviates by $4 \%$ and the $\mathrm{BCC}$ lattice by $27 \%$ in the width value, and finally in the length values. On the other hand, it was determined that the primitive lattice deviated by $3 \%$ and the $\mathrm{BCC}$ lattice deviated by $55 \%$.

Keywords: Additive manufacturing, Selective laser melting, TPMS lattice structure, Dimensional accuracy

eklemeli imalat yöntemleri arasında toz yataklı füzyon (TYF) tekniği ile hassas üretimler gerçekleștirilmektedir [8]. TYF tekniği ise SLE, seçmeli lazer sinterleme (SLS) ve elektron 1şınlı ergitme (EIE) olmak üzere üç gruba ayrılmaktadır [8]. Bu yöntemler arasında SLE üretimde sağladığı hassasiyet, yüksek yoğunluk ve ürün dayanıklılığından kaynaklı olarak genellikle tercih edilmektedir [9, 10]. Ayrıca SLE yönteminde üretim malzemesi olarak $\mathrm{CoCr}$, Ti6Al4V ve $316 \mathrm{~L}$ gibi farkl alaşımların tozları kullanılmaktadır. Bu malzemeler arasında birçok endüstriyel alanda sağladığı yüksek mukavemet, yüksek korozyon direnci nedeni ile $\mathrm{CoCr}$ tozu tercih edilmektedir. Özellikle yüksek biyouyumluluk özelliği ile diz ve kalça eklem protezleri başta olmak üzere biyomedikal alanda kullanılmaktadır.

\footnotetext{
* Sorumlu yazar / Corresponding author, e-posta / e-mail: ender.emir@ istiklal.edu.tr (E. Emir)

Geliș / Recieved: 26.11.2021 Kabul / Accepted: 21.01.2022 Yayımlanma / Published: 15.04.2022

doi: 10.28948/ngmuh.1027480
} 
Ancak üretim parametreleri ve üretim esnasinda meydana gelen kusurlar oluşturulmak istenen kafes geometrisinin beklenen hassasiyet ve doğruluk düzeyinde üretilmesinde etkili bir rol oynamaktadır. Özellikle bu yöntemde küçük ölçekli parçaların üretiminde toz bileşimi, toz boyutu, tezgâh özellikleri, lazer gücü, tarama hızı, tarama stratejisi parametrelerine bağlı olarak tasarlanan parça ile üretilen parça arasında boyutsal uyuşmazlıklar ortaya çıkmaktadır [11, 12]. Belirtilen üretim parametreleri güç kaynağından çıkan lazer 1şının eriyik havuzunun boyutlarını da doğrudan etkilemektedir.

Literatürde SLE yöntemi ile üretimde boyutsal hassasiyetin bozulmasinda eriyik metal havuzunun boyutlarının değişiminin neden olduğu bazı üretim kusurları belirtilmiştir [13-16]. Bu kusurlardan en önemlileri merdiven etkisi [13], kütle birikimi [14] ve yapışmış partikül [15, 16] oluşum mekanizmalarıdır. Özellikle merdiven etkisi ve yapışmış partikül oluşumu, SLE ile üretimde parçaların üretim doğruluğunu tanımlamada tipik olarak kilit faktörlerdir [17]. Yapışmış partikül mekanizmanın oluşumu lazer, kullanılan toz, çevresel faktörler, katılaşmış ilk toz katmanı ile bir sonraki serilen toz katmanı arasında meydana gelen fiziksel ve kimyasal reaksiyonlar gibi toplamda 4 farkl termal ve dinamik durumu içerir $[16,18]$. Bunlar katının mekanik, katı hal dönüşümü, termal akışkan dinamiği ve partikül dinamiğidir. Wang vd. [16] sabit tarama hızına karşın farklı lazer güçlerinin yapışmış partikül oluşumu üzerine olan etkilerini araştırmışlar ve lazer gücünün yapışmış partikül oluşumunda etkili bir faktör olduğunu söylemişlerdir.

Merdiven etkisi ise üretilen bileșenlerin boyutsal doğruluğunu etkileyen SLE dahil olmak üzere birçok EI yönteminde ortak olan iyi bilinen bir olgudur [19]. Katman bazlı üretim süreci nedeniyle, açılı yüzeyler, katman kalınlığ boyutlu çıkıntılarla imal edilerek, amaçlanan ve imal edilen geometriler arasındaki boyutsal sapmaları arttırmaktadır [13]. Strano vd. [20] çalışmalarında merdiven basamağ etkisi, inşa edilen kafes yapısının nihai boyutlarını etkilediğini rapor etmişlerdir. Diğer yandan SLE işlemi esnasında ortaya çıkan yüksek seviyelerdeki ısının dış ortama atılması esnasında da malzemede meydana gelebilecek çekmeler ve artık termal gerilmeler boyutsal doğruluğu etkilemektedir [12]. Son olarak ise stereolitografi (STL) dosyası olarak oluşturulan CAD modelde üçgen yaklaşımı ile dönüştürme işlemi gerçekleştirdiğinden dolayı küçük miktarlarda sapmalarda meydana gelmektedir [12].

$\mathrm{Bu}$ çalışmada SLE yöntemi kullanılarak $\mathrm{CoCr}$ tozundan üretilen ÜPMY bazlı kafes yapılı biyomalzemelerin üretiminde karşılaşılan boyutsal sapmaların belirlenebilmesi üzerine bir çalışma sunmak amaçlanmıştır. Çalışmada \%10 nispi yoğunluğa sahip ÜPMY bazlı ilkel kafes ve HMK kafes yapıları üretilmiştir. Üretim sonrası boyutsal doğruluğun değerlendirilebilmesi için taramalı elektron mikroskobu (TEM) ve micro-CT ile alınan görüntülerden ölçümler gerçekleştirilmiştir. Ayrıca deneysel verilerin desteklenmesi için SLE üretim süreci SEA kullanılarak simüle edilmiştir.

\section{Materyal ve metot}

\subsection{Materyal}

$\mathrm{Bu}$ çalışmada biyomedikal uygulamalarda çoğunlukla tercih edilen kimyasal bileşimi Tablo 1'de verilmiş olan CoCr tozu kullanılmıştır. Özellikle metal tozları kullanılarak gerçekleştirilen üretimlerde tozların tane boyutları üretim hassasiyeti açısından önemli bir parametredir. Bu nedenle toz partikül boyutunun değerlendirilebilmesi için $\mathrm{CoCr}$ tozundan TEM görüntüsü alınmıştır (Şekil 1a) ve toz partikül boyutu dağılımının ölçümleri yapılmıştır (Şekil 1b).

Tablo 1. CoCr toz kimyasal bileşimi [21]

\begin{tabular}{llllllll}
\hline \multicolumn{7}{c}{ Element içeriği (\%) } \\
\hline Alaşım & Co & Cr & Mo & W & V & Nb & Fe \\
Oran(\%) & $62 \pm 1$ & $25 \pm 1$ & $7 \pm 1$ & $6 \pm 1$ & 0.2 & 0.2 & $0.2 \pm 0.1$ \\
\hline
\end{tabular}

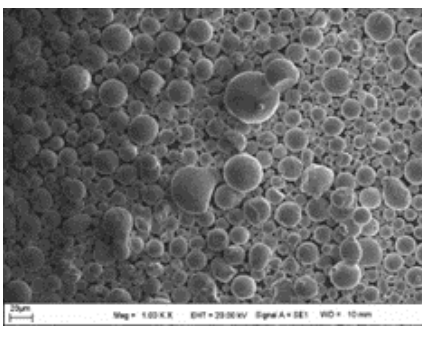

(a)

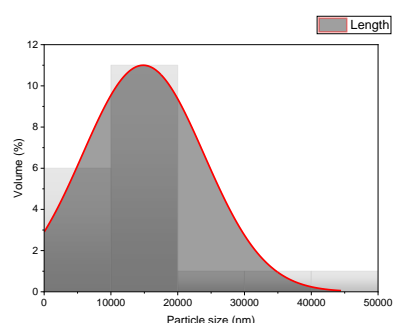

(b)
Şekil 1. (a) Başlangıç tozlarının TEM görüntüsü (b) $\mathrm{CoCr}$ toz partikül boyutu dağılımları

\subsection{Metot}

\subsubsection{Kafes yapılarının tasarımı ve üretimi}

Çalışmada 4x4x4 birim hücre boyutlarında tasarlanan ÜPMY bazlı ilkel kafes ve HMK kafes yapıları kullanılmıştır. Literatür çalışmalarında ÜPMY bazlı kafes yapilarının tasarlanmasinda seviye set denklemleri tanımlanmaktadır [22-24]. Bu nedenle her iki kafes yapısının tasarımı için Denklem (1) ve Denklem (2) verilmiş olan seviye set denklemleri tanımlanmıştır.

$$
\begin{aligned}
& \text { Фं்lkel kafes }=\cos (k x \cdot x)+\cos (k y \cdot y)+\cos (k z \cdot z)=q \\
& \quad \Phi H M K \\
& \quad=\cos (2 * k x \cdot x)+\cos (2 \cdot k y \cdot y) \\
& \quad+\cos (2 \cdot k z \cdot z)-(2 \cdot(\cos (k x \cdot x) \cdot \cos (k y \cdot y) \\
& \quad+\cos (k y \cdot y) \cdot \cos (k z \cdot z)+\cos (k z \cdot z) \cdot \cos (k x \cdot x)))=q
\end{aligned}
$$

Burada her bir numune için kullanılan q parametresi kafes yapılarının gözeneklilik boyutunu belirleyen faktördür [25]. Diğer yandan ki $(i=x, y, z) x, y, z$ yönlerinde birim hücre boyutunu kontrol etmek için kullanılan ÜPMY kafes yapıları için fonksiyonel periyodiklerdir. $\mathrm{Bu}$ fonksiyonel periyodikler Denklem (3)'de verildiği gibi ifade edilebilir:

$$
k i=2 . \pi \cdot(n i / L i)
$$

Burada; ni x,y,z yönlerindeki birim kafes miktarlarıdır. Li ise $x, y, z$ yönlerindeki ni sayıdaki birim hücrelerin mutlak boyutlarıdır. Ek olarak kafes yapısının genel boyutlarının oluşturulması için $\mathrm{x}, \mathrm{y}, \mathrm{z} \in[-2 \pi, 2 \pi]$ olarak belirlenmiştir. 
Yukarıda verilmiş olan tüm parametreler kullanılarak oluşturulan kafes yapıları CAD modelleri Şekil 2'de verilmiştir. Tasarım aşamasından sonra $G$ kodları oluşturulan kafes yapıları Consept Laser Mlab Cusing marka SLE üretim teknolojisine sahip metal 3D yazıcı kullanılarak üretilmiştir (Şekil 3). Bu yapıların üretimi için SLE işleme parametreleri $100 \mathrm{~W}$ lazer gücü, $1200 \mathrm{~mm} / \mathrm{s}$ tarama hızı, 30 $\mu \mathrm{m}$ katman kalınlı̆̆

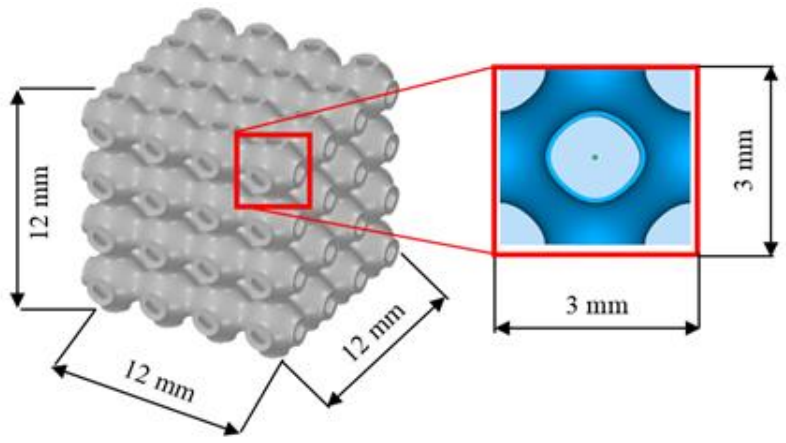

(a)

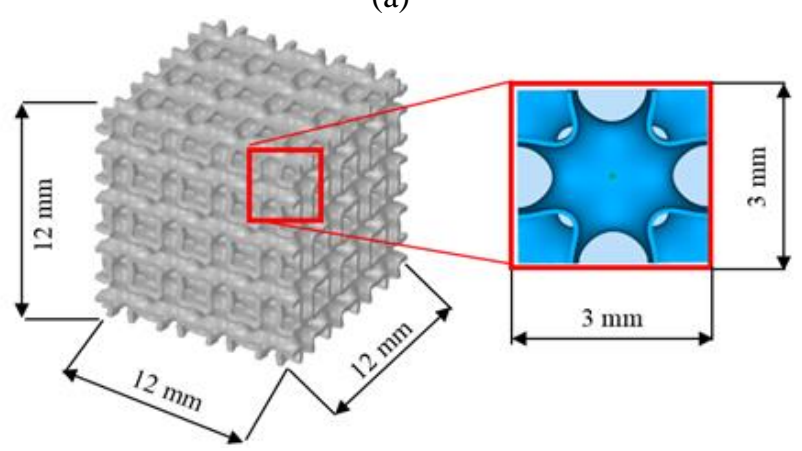

(b)

Şekil 2. ÜPMY kafes yapıları; (a) ilkel kafes, (b) HMK

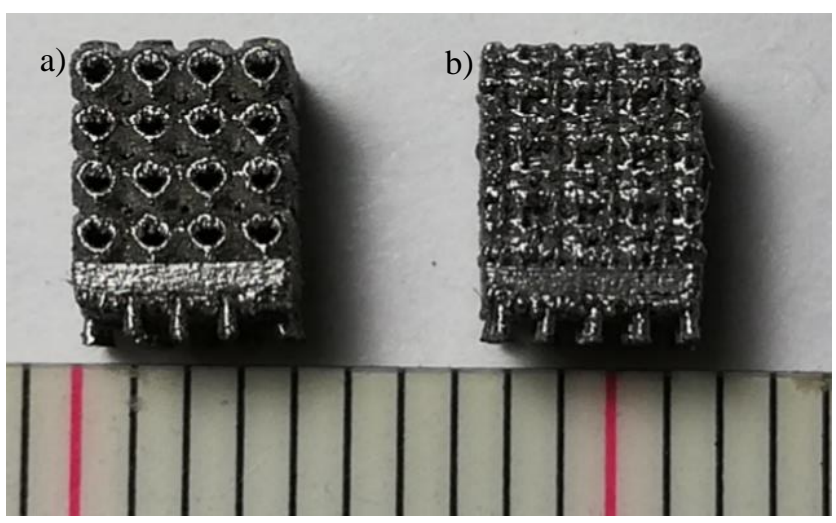

Şekil 3. SLE yöntemi ile üretilen kafes yapıları; (a) ilkel kafes, (b) HMK

\subsubsection{Boyutsal sapmaların ölçüm stratejisi}

Çalışmanın bu aşamasında mikroskop görüntülerinin CAD model ile karşılaştırılabilmesi için öncelikli olarak Şekil 4a-4b'de gösterildiği gibi birim hücrelerin boyutları belirlenmiştir. Ölçümler alınırken her bir birim hücrenin gözeneklerinin genişliği (W), uzunluğu (L), radyus (R) ve kalınlık (t) değerleri dikkate alınmıştır. Tablo 2'de birim hücrelerin boyutları verilmiştir. Alınan ölçümler soncunda ortalama değerler hesaplanmıştır. Son aşamada HMK ve ilkel kafes yapılarının her biri için CAD model ve mikroskop görüntüleri karşılaştırılmıştır. Ayrıca kafes yapısında meydana gelen pozitif ve negatif sapmaların 3 boyutlu olarak ölçülebilmesi için her iki kafes yapısından micro-CT görüntüleri alınarak CAD model ile karşılaştırılmıştır.

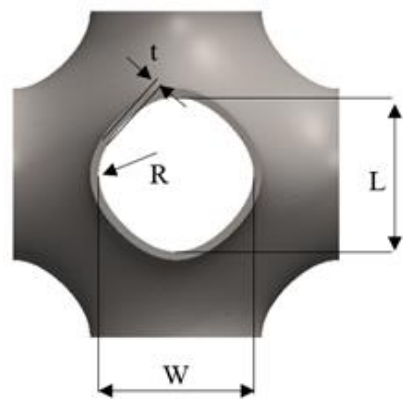

(a)

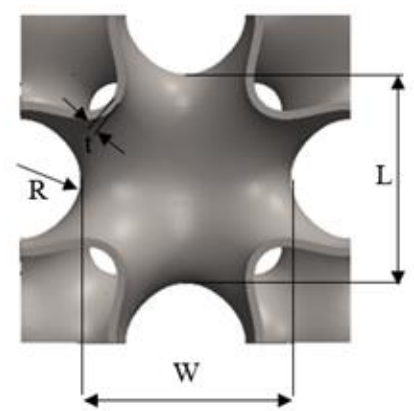

(b)
Şekil 4. Birim hücre boyutları; (a) ilkel kafes, (b) HMK

Tablo 2. Birim hücre boyutları

\begin{tabular}{lll}
\hline & İlkel kafes & HMK \\
\hline Radyus (R) & 0.415 & 0.475 \\
Kalınlık (t) & 0.3 & 0.3 \\
Genişlik (W) & 1.071 & 1.21 \\
Uzunluk (L) & 1.071 & 1.21 \\
\hline
\end{tabular}

\subsubsection{Sonlu elemanlar modeli}

SLE yöntemi kullanılarak gerçekleştirilen üretimlerde nihai ürünlerde meydana gelen isı boyutsal hassasiyeti büyük ölçüde etkilemektedir. Özellikle üretilen geometri ile inşa edilen tabla ve diş ortama belirli bir miktar 1sı transferi meydana gelmektedir. Ancak belirtilen parametrelerin ölçümü deneysel çalışmalar ile hem zaman almakta hem de maliyetli olmaktadır. Bu nedenle ürerim anındaki 1sı transfer oluşumu ve deformasyon büyüklüklerinin belirlenmesi için sonlu elemanlar yazılımı kullanılmıştır. Böylece üretim süreçleri simüle edilerek SLE yöntemi ile üretimde meydana gelen 1sıl gerilmeler ve buna bağlı olarak oluşan deformasyon bölgeleri ve büyüklükleri elde edilmiștir. Şekil 5'de eklemli imalat simülasyonunun oluşturulmasında kullanılan 4x4x4'lik kafes yapıları, taban plakaları ve inşa yönü görülmektedir.

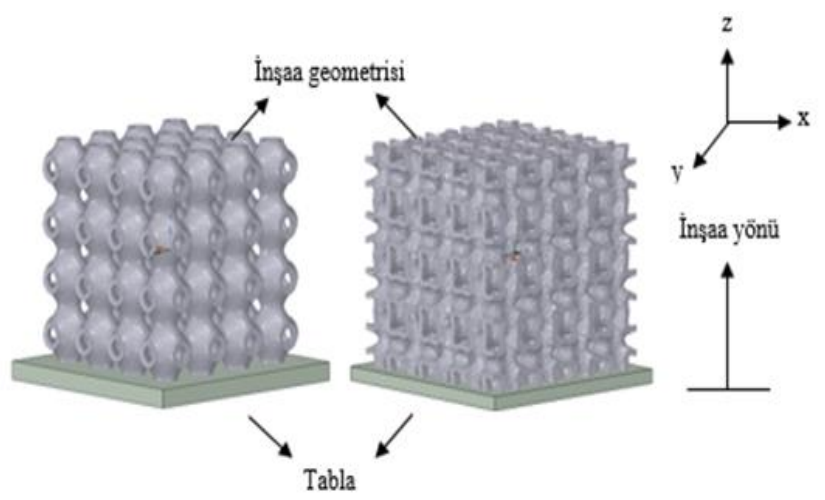

Şekil 5. SEA eklemeli imalat prosesi 


\section{Bulgular ve tartışma}

\subsection{SLE üretim hassasiyeti}

$\mathrm{Bu}$ bölümde ilkel kafes ve HMK birim hücrelerinde meydana gelen boyutsal sapma büyüklüklerinin tespiti için alınan ölçüm sonuçları verilmiştir. Görüntüler incelendiğinde her bir birim hücrede kalınlık, genişlik ve uzunluk ölçülerinde belirgin farklıkların meydana geldiği görülmüştür. Tablo 3'de her iki birim hücrenin kalınlık, genişlik, uzunluk ve radyus değerlerinde meydana gelen boyutsal sapmaların ortalama değerleri verilmiştir. Kalınlık ölçümleri sonucunda ilkel kafes birim hücrede kalınlığın CAD model verisinden $(0,3 \mathrm{~mm})$ ortalama \%15 saptığı, HMK birim hücrede ise olması gereken kalınlık değerinden $(0,3 \mathrm{~mm})$ ortalama \%32 saptığı tespit edilmiştir. Genişlik bakımından ise ilkel kafes birim hücrede ortalama $\% 4$ sapma, HMK birim hücrede ise ortalama \%27 sapma değeri ölçülmüştür. Son olarak her iki birim hücrenin uzunluk ölçüm sonuçları karşılaştırıldığında ise ilkel kafes birim hücrede \%3 sapma, HMK birim hücrede ise \%55 sapma meydana geldiği gözlemlenmiştir.

Tablo 3. Birim hücre ortalama boyut ölçüm değerleri

\begin{tabular}{llllll}
\hline & & $\begin{array}{l}\text { Kalınlık } \\
(\mathrm{t})\end{array}$ & $\begin{array}{l}\text { Genişlik } \\
(\mathrm{W})\end{array}$ & $\begin{array}{l}\text { Uzunluk } \\
(\mathrm{m})\end{array}$ & $\begin{array}{l}\text { Radyus } \\
(\mathrm{R})\end{array}$ \\
\cline { 3 - 6 } & & $(\mathrm{mm})$ & $(\mathrm{mm})$ & $(\mathrm{mm})$ & $(\mathrm{mm})$ \\
\cline { 3 - 6 } Ilkel & CAD & 0.3 & 1.071 & 1.071 & 0.415 \\
\multirow{2}{*}{ HMKes } & Deneysel & 0.345 & 1.120 & 1.103 & 0.341 \\
& CAD & 0.3 & 1.21 & 1.21 & 0.475 \\
& Deneysel & 0.398 & 0.893 & 0.665 & 0.16 \\
\hline
\end{tabular}

Birim hücrelerin kalınlık ölçülerindeki sapmaların temelinde merdiven etkisi adı verilen SLE yöntemi ile üretimde sıklıkla karşılaşılan oluşum gelmektedir. Şekil 6'da merdiven etkisinin oluşumunun şematik olarak gösterimi verilmiştir. Bu durumun oluşumundaki temel sebep üretim esnasında katman kalınlığı ile lazer eriyik derinliğinin birbirinden farklı olmasından kaynaklıdır. Lazer eriyik derinliğinin fazla olması ile birlikte lazer ışınlarının etki ettiği alanda yatay mesafede artmaktadır [15]. Böylece eğimli yüzeylerin üretiminde yatay bölgedeki eriyik tozları CAD model verisine göre daha fazla alana yayılmakta ve sonuç olarak inşa yönünde giderek artan çıkıntı yapıların oluşmasına neden olmaktadır. Özellikle bu oluşum mekanizmasında eğimli yüzeylerin üretiminde her bir katmanın üzerine yeni bir katman inşa edildiği zaman katman kalınlığ 1 boyutlu çıkıntılarla üretime sebep olmaktadır. İlkel kafes ve HMK birim hücrede eğimli yüzeyler incelendiğinde kalınlık ölçümleri inşa yönünde giderek artış göstermiştir (Șekil 7). Kalınlık ölçüm sonuçları ilkel kafeste $0.3 \mathrm{~mm}$ olması gereken kalınlık değeri merdiven etkisinin oluşumu ile birlikte minimum $0.308 \mathrm{~mm}$, maksimum $0.322 \mathrm{~mm}$ değerine kadar çıktığı görülmüştür. Diğer yandan HMK birim hücrede ise minimum $0.267 \mathrm{~mm}$ iken maksimum $0.307 \mathrm{~mm}$ değerleri ölçülmüştür. Nitekim literatür çalışmaları incelendiğinde de SLE yöntemi ile üretimde eğimli yüzeylerin üretiminde merdiven etkisinin oluşumu yönünde çalışmalar elde edilen sonuçları destekler niteliktedir [19].

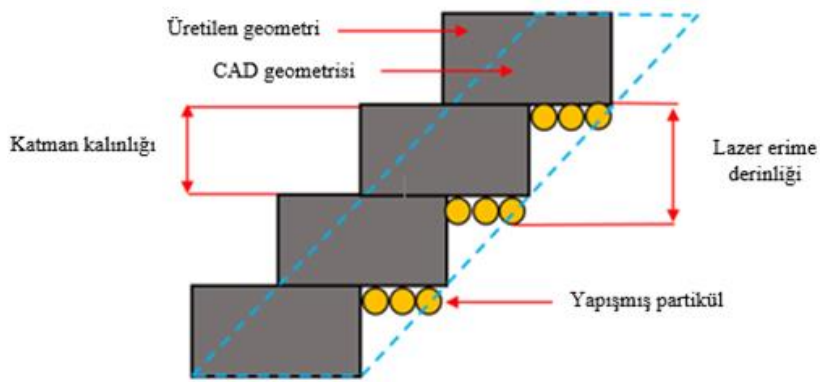

Şekil 6. Merdiven etkisi oluşumunun şematik gösterimi

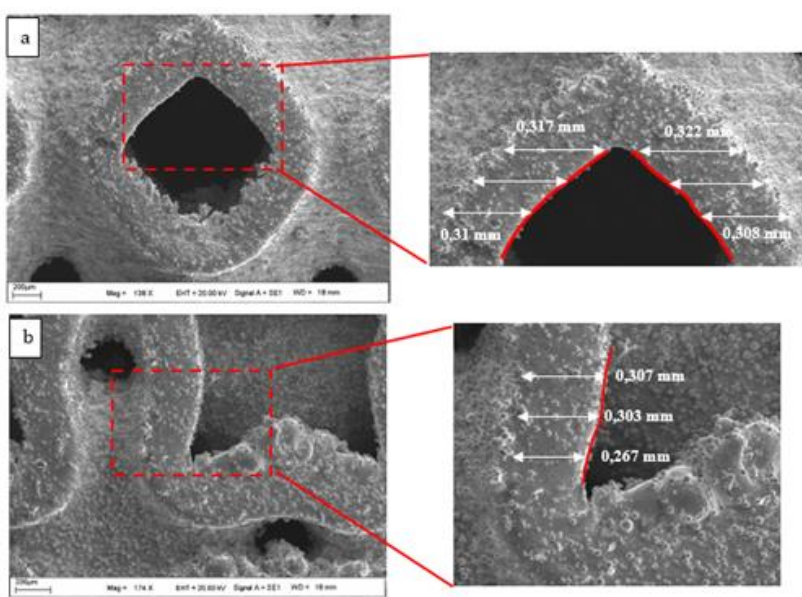

Şekil 7. Merdiven etkisi oluşumu; (a) ilkel kafes, (b) HMK

Ayrıca birim hücrelerin radyusa sahip bölgelerinde de boyutsal sapmaların meydana geldiği net bir şekilde görülmüştür. Tablo 3'de yer alan veriler incelendiğinde ilkel kafes birim hücrenin radyus değerinin CAD model verisine göre \%18 sapma meydana geldiği, HMK birim hücrede ise CAD model verisinden \%33 sapma oluştuğu tespit edilmiştir. $\mathrm{Bu}$ durum birim hücrenin inşa yönüne göre alt kısımlarda kalan kütle birikmesi olarak adlandırılan ve metal malzemelerin SLE yöntemi ile üretiminde sıklıkla karşılaşılan eklemeli imalatta boyutsal hassasiyeti etkileyen bir yapıdan kaynaklanmaktadır. Nitekim Şekil 8'de verilmiş olan görüntülerde de belirgin şekilde kütle birikimi oluşumu gözlemlenmiştir. Bu üretim kusurunun oluşmasında iki farklı neden vardır. Bunlardan birincisi nano boyutta bulunan CoCr tozlarının yüzey enerjileri fazla olması nedeni ile toz partikülleri yüzey enerjilerini azaltmak için bir araya gelmesidir [14]. Diğer neden ise toz partikülleri arasındaki Van der Walls ve Coulamb kuvveti birikim oluşumunu sağlayan kuvvetlerdir [14].

Ayrıca birim hücrede meydana gelen boyutsal sapmaların oluşumu ve büyüklüklerinin yorumlanabilmesi için Şekil 9'da verilen SEA ile incelenmiştir. Analiz sonuçları inşa yönüne bağlı ve inşa yönünden bağımsız olarak değerlendirilmiştir. Şekil 9a ve Şekil 9b'de verilen ilkel kafes birim hücrede inşa yönünde ve inşa yönünden 
bağımsız meydana gelen deformasyon büyüklüklerinin gösteren SEA sonuçları verilmiştir.

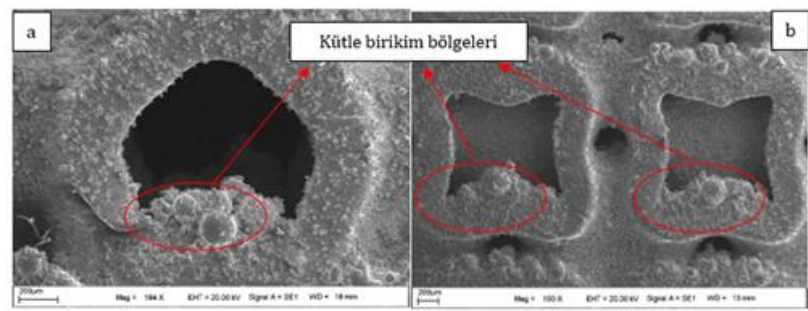

Şekil 8. Birim hücrede meydana gelen geometrik sapma alanlar1; (a) ilkel kafes, (b) HMK

Sonuçlar incelendiğinde ilkel kafes birim hücrede $+\mathrm{z}$ ekseni boyunca maksimum deformasyon büyüklüğü 0.20189 $\mathrm{mm}$ iken toplam deformasyon büyüklüğü ise $0.28262 \mathrm{~mm}$ iken; HMK birim hücrede ise $+z$ ekseni boyunca maksimum deformasyon büyüklüğü $0.3181 \mathrm{~mm}$ iken toplam deformasyon büyüklüğü ise $0.33971 \mathrm{~mm}$ olduğu görülmüştür (Şekil 9c, Şekil 9d). Özellikle SEA sonuçlarında verilmiş olan renk skalası incelendiğinde maksimum deformasyona bölgelerinin deneysel çalışma ile elde edilen deformasyon bölgeleri ile benzer sonuçlar sergilediği tespit edilmiştir.
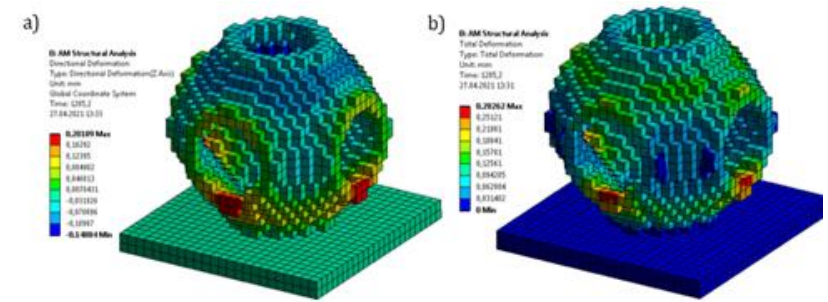

c)

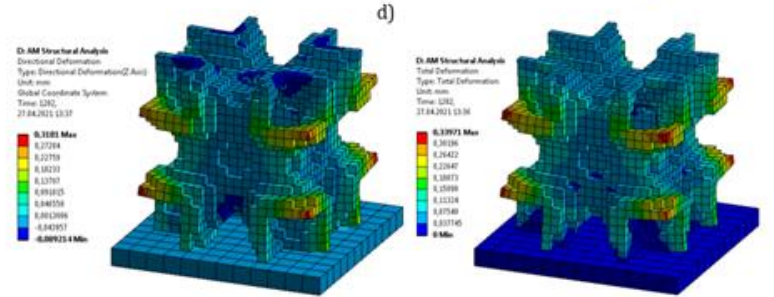

Şekil 9. Üretim esnasında meydana gelen deformasyon büyüklüklerinin FE sonuçları; (a) ilkel kafes birim hücrenin z yönündeki deformasyon miktarı, (b) ilkel kafes birim hücrenin toplam deformasyon miktarı, (c) HMK birim hücrenin $\mathrm{z}$ yönündeki deformasyon miktarı, (d) HMK birim hücrenin toplam deformasyon miktarı

Şekil 10'da ilkel kafes ve HMK kafes yapıları için verilmiş olan TEM görüntülerinde de belirgin bir şekilde yapışmış toz partiküllerinin oluşumuna rastlanmıştır. $\mathrm{Bu}$ mekanizmanın oluşumuna sebep olan eriyik havuzunun termodinamik, dinamik ve metalürjik yönden karasızlığ sonucu üretim esnasında meydana gelen birkaç durum vardır [26]. Bunlardan birincisi üretim için oluşturulan eriyik havuzunu genişliği ve derinliğinin CAD model boyutlarına göre daima fazla olmasıdır [15, 27]. İkincisi ise lazer ışını ile tozların taranması anında yüzeylere oluşan yüksek 1sı ile birlikte nispeten erimiş olan toz partikülleri bağlanmaktadır [15]. Nitekim Şekil 11'de SLE yöntemi ile üretim esnasında meydana gelen termal ve dinamik olayların değişimi şematik olarak verilmiştir. Bağlanan bu toz partikülleri bir sonraki serilen toz katmanının ürerine düşen lazer ışının etkisi ile meydana gelen 1sı transferi sonucunda soğuma ile yapışmaya neden olmaktadır. Son olarak ise lazer tarama yönünde gaz genleşmesi nedeni ile partikül sürüklenmesi olayı gerçekleşmektedir. Bu olay sonucunda üretim alanında toz partikülleri savrulurken kısmen katılaşmaya başlamış yüzeylerin üzerine yapışmaktadır.
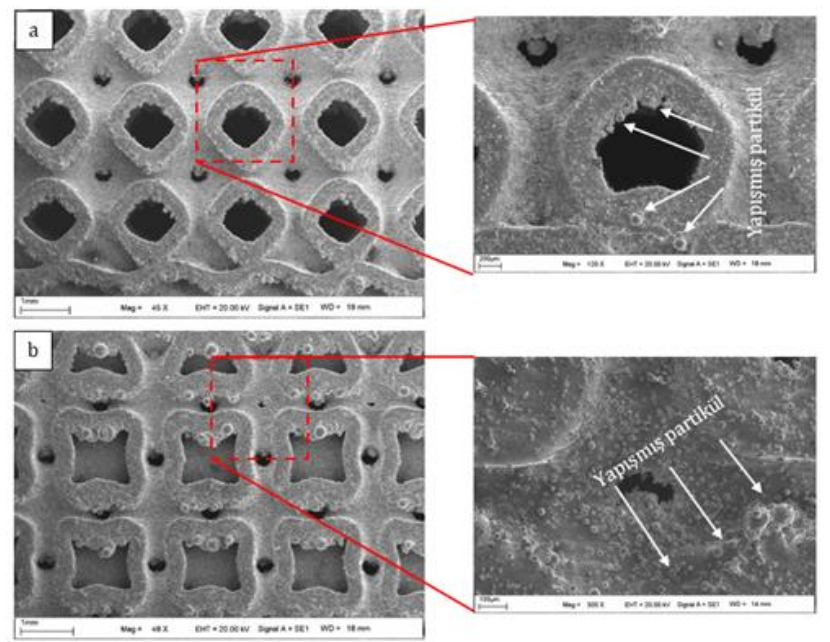

Şekil 10. Yapışmış partikül oluşumu; (a) ilkel kafes, (b) HMK

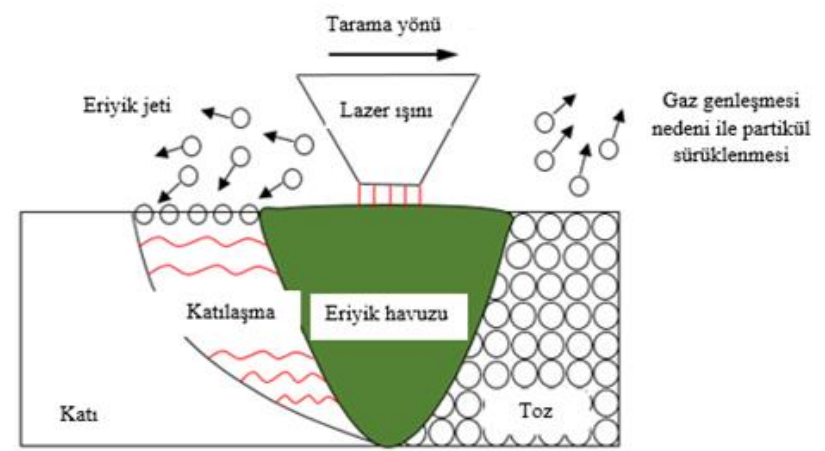

Şekil 11. SLE üretim prosesi

Diğer yandan birim hücrelerdeki boyutsal sapmalara karşılık tüm kafes yapısının da belirgin bir şekilde etkilendiği görülmüştür. Özellikle birbiri ile komşu olan birim hücrelerin arasındaki yatay ve dikey mesafelerde sapmaların meydana geldiği tespit edilmiştir. Şekil 12'de verilen görüntüler incelendiğinde ilkel kafes yapısında her bir birim hücre arasındaki ortalama dikey mesafe CAD model verisinden $(0,3 \mathrm{~mm})$ ortalama \%59.33 sapma, yatay mesafelerde ise CAD model verisinden $(0.3 \mathrm{~mm})$ ortalama \%26 sapma tespit edilmiştir. HMK kafes yapısında ise her bir birim hücre arasındaki ortalama dikey mesafe CAD model verisinden $(0,3 \mathrm{~mm})$ ortalama $\% 56.33$ sapma, yatay mesafelerde ise CAD model verisinden $(0,3 \mathrm{~mm})$ ortalama \%69.33 sapma meydana geldiği görülmüştür. 

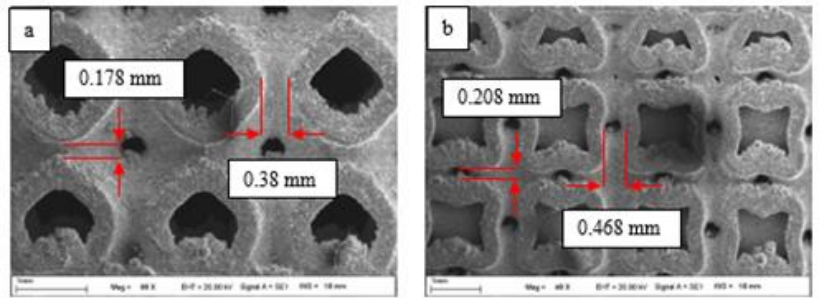

Şekil 12. Komşu hücreler arası yatay ve dikey mesafe farklılıkları; (a) ilkel kafes, (b) HMK

Şekil 13'de SLE yöntemi ile üretimde meydana gelen boyutsal sapmaların 3 boyutlu tespiti için üst üste bindirilen micro-CT ve CAD model görüntüleri verilmiștir. Elde edilen sonuçlarda boyutsal sapmaların ilkel kafes yapısında nominal değerden $+0.27 /-0.26 \mathrm{~mm}$ saptı̆̆ı, HMK kafes yapısında ise $+0.35 /-0.33 \mathrm{~mm}$ saptı̆̆ı görülmüștür. İnşa yönünde giderek artan 1sı birikimi nedeni ile her iki kafes yapısında da meydana gelen sapmalarda da artış gözlemlenmiştir. Meydana gelen isının kontrollü bir şekilde transfer edilememesi eriyik havuzunda giderek artan şekilde yapışmış partikül oluşumuna sebep olur. Ayrıca 2 boyutlu ölçümlerde merdiven etkisi ve kütle birikimi nedeni ile meydana gelen boyutsal sapmalar 3 boyutlu ölçümler sonucunda elde edilen değerler ile desteklenmiştir

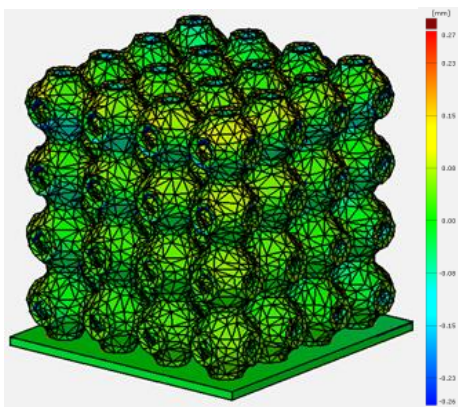

(a)

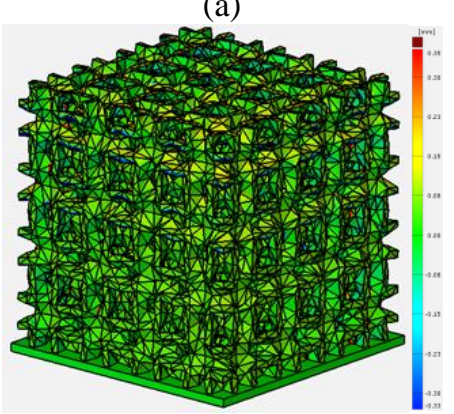

(b)

Şekil 13. Boyutsal sapmaların 3 boyutlu gösterimi; (a) ilkel kafes, (b) HMK

\section{Sonuçlar}

$\mathrm{Bu}$ çalışmada CAD ortamında tasarlanmış \%10 nispi yoğunluğa sahip ÜPMY bazlı ilkel kafes ve HMK kafes yapıları SLE yöntemi kullanılarak üretilmiştir. Çalışmadaki temel amaç SLE yöntemi ile üretimde ÜPMY bazlı ilkel kafes ve HMK kafes yapılarının üretim sonrası geometrik hassasiyetlerini karşılaş̧ırmaktır. Bu çalış̧madan elde edilen başlıca bulgular ve sonuçlar aşağıdaki şekilde sıralanabilir:
1. Elde edilen sonuçlarda geometrik hassasiyetin tasarlanan CAD modeli ile üretilen kafes yapısı arasında belirgin bir şekilde farkların oluşumu gözlemlenmiştir.

2. Birim hücrelerin boyutları incelendiğinde genişlik ve kalınlığın kütle birikimi ve merdiven etkisi kaynaklı oluşumu ile meydana geldiği tespit edilmiştir.

3. Üretim esnasında meydana gelen isı geçişleri ve buna bağlı olarak oluşan yapışmış partikül mekanizması ile birim hücrenin uzunluk ölçülerinde belirgin farklılıklar tespit edilmiştir.

4. Üretim sürecinde inșa yönünde meydana gelen deformasyon büyüklükleri ve toplam meydana gelen deformasyon büyüklükleri için gerçekleştirilen SEA sonuçlarında da deneysel elde edilen büyüklüklerde ve bölgelerde sonuçlar birbiri ile tutarlı olduğu görülmüştür.

5. Micro-CT ölçümleri ile incelenen 3 boyutlu sapmaların merdiven etkisi, kütle birikimi ve yapışmış partikül oluşumu ile ilişkili olduğu sonucu desteklenmiştir.

\section{Çıkar çatışması}

Yazarlar çıkar çatışması olmadığını beyan etmektedir.

\section{Benzerlik oranı (iThenticate): $\% 9$}

\section{Kaynaklar}

[1] J. Zhang, B. Song, L. Yang, R. Liu, L. Zhang and Y. Shi, Microstructure evolution and mechanical properties of $\mathrm{TiB} / \mathrm{Ti} 6 \mathrm{Al} 4 \mathrm{~V}$ gradient-material lattice structure fabricated by laser powder bed fusion. Composites Part B: Engineering, 202, 108417, 2020. doi:10.1016/j.compositesb.2020.108417.

[2] L. Zhang, B. Song, J. J. Fu, S. S. Wei, L. Yang, C. Z. Yan and Y. S. Shi, Topology-optimized lattice structures with simultaneously high stiffness and light weight fabricated by selective laser melting: Design, manufacturing and characterization. Journal of Manufacturing Processes, 56, 1166-1177, 2020. https://doi:10.1016/j.jmapro.2020.06.005.

[3] S. Yin, H. Chen, Y. Wu, Y. Y. Li and J. Xu, Introducing composite lattice core sandwich structure as an alternative proposal for engine hood. Composite Structures, 201, 131-140, 2018. https://doi:10.1016/j.compstruct.2018.06.038.

[4] J. Parthasarathy, B. Starly and S. Raman, A design for the additive manufacture of functionally graded porous structures with tailored mechanical properties for biomedical applications. Journal of Manufacturing Processes, 13(2), 160-170, 2011. https://doi:10.1016/j.jmapro.2011.01.004.

[5] A. Gupta and M. Talha, Recent development in modeling and analysis of functionally graded materials and structures. Progress in Aerospace Sciences, 79, 114, 2015. https://doi:10.1016/j.paerosci.2015.07.001.

[6] C. Pan, Y. Han and J. Lu, Design and Optimization of Lattice Structures: A Review. Applied Science, 10,6374, 2020. https://doi:10.3390/app10186374.

[7] C. H. P. Nguyen, Y. Kim and Y. Choi, Design for Additive Manufacturing of Functionally Graded Lattice Structures: A Design Method with Process Induced Anisotropy Consideration. International 
Journal of Precision Engineering and Manufacturing-

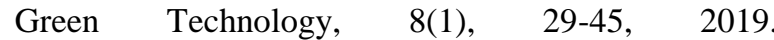
https://doi:10.1007/s40684-019-00173-7.

[8] D. Mahmoud and M. Elbestawi, Lattice Structures and Functionally Graded Materials Applications in Additive Manufacturing of Orthopedic Implants: A Review. Journal of Manufacturing and Materials Processing, 1(2), 13, 2017. https://doi:10.3390/jmmp1020013.

[9] A. Alghamdi, T. Maconachie, D. Downing, M. Brandt, M. Qian and M. Leary, Effect of additive manufactured lattice defects on mechanical properties: an automated method for the enhancement of lattice geometry. The International Journal of Advanced Manufacturing Technology, 108(3), 957-971, 2020. https://doi:10.1007/s00170-020-05394-8.

[10] L. Jiao, Z. Chua, S. Moon, J. Song, G. Bi and H. Zheng, Femtosecond Laser Produced Hydrophobic Hierarchical Structures on Additive Manufacturing Parts. Nanomaterials, 8(8), 6012018. https://doi:10.3390/nano8080601.

[11] Z. S. Bagheri, D. Melancon, L. Liu, R. B. Johnston and D. Pasini, Compensation strategy to reduce geometry and mechanics mismatches in porous biomaterials built with Selective Laser Melting. Journal of the Mechanical Behavior of Biomedical Materials, 70, 1727, 2017. https://doi:10.1016/j.jmbbm.2016.04.041.

[12] J. Kozak and Zakrzewski, Accuracy problems of additive manufacturing using SLS/SLM processes, 020010, 1-12, 2018. https://doi:10.1063/1.5056273.

[13] T. Maconachie, M. Leary, B. Lozanovski, X. Zhang, M. Qian, O. Faruque and M. Brandt, SLM lattice structures: Properties, performance, applications and challenges. Materials \& Design, 108137, 2019. https://doi:10.1016/j.matdes.2019.108137.

[14] W. Zhai, W. Zhou, L. M. S. Nai and J. Wei, Characterization of nanoparticle mixed $316 \mathrm{~L}$ powder for additive manufacturing. Journal of Materials Science \& Technology, 47, 162-168, 2020. https://doi:10.1016/j.jmst.2020.02.019.

[15] S. L. Sing, F. E. Wiria and W. Y. Yeong, Selective laser melting of lattice structures: A statistical approach to manufacturability and mechanical behavior. Robotics and Computer-Integrated Manufacturing, 49, 170-180, 2018. https://doi:10.1016/j.rcim.2017.06.006.

[16] D. Wang, S. Wu, F. Fu, S. Mai, Y. Yang, Y. Liu and C. Song, Mechanisms and characteristics of spatter generation in SLM processing and its effect on the properties. Materials \& Design, 117, 121-130, 2017. https://doi:10.1016/j.matdes.2016.12.060.

[17] L. Yang, M. Ferrucci, R. Mertens, W. Dewulf, C. Yan, Y. Shi and S. Yang, An investigation into the effect of gradients on the manufacturing fidelity of triply periodic minimal surface structures with graded density fabricated by selective laser melting. Journal of
Materials Processing Technology, 116367, 2019. https://doi:10.1016/j.jmatprotec.2019.116367.

[18] J. P. Kruth, G. Levy, F. Klocke, and T. H. C. Childs, Consolidation phenomena in laser and powder-bed based layered manufacturing. CIRP Annals, 56(2), 730-759, 2007. https://doi:10.1016/j.cirp.2007.10.004.

[19] M. A. Isa and I. Lazoglu, Five-axis additive manufacturing of freeform models through buildup of transition layers, Journal of Manufacturing System, 50, 69-80, 2019. https://doi:10.1016/j.jmsy.2018.12.002.

[20] G. Strano, L. Hao, R. M. Everson, and K. E. Evans, Surface roughness analysis, modelling and prediction in selective laser melting. J. Mater. Process. Technol. 213, 589-597, 2013. https://doi:10.1016/j.jmatprotec.2012.11.011.

[21] M. V. Mergulhão, C. E. Podestá and M. D. M. das Neves, Mechanical Properties and Microstructural Characterization of Cobalt-Chromium ( $\mathrm{CoCr}$ ) Obtained by Casting and Selective Laser Melting (SLM). Materials Science Forum, 899, 534-539, 2017. https://doi:10.4028/www.scientific.net/msf.899.534.

[22] M. Zhao, F. Liu, G. Fu, D. Zhang, T. Zhang and H. Zhou, Improved Mechanical Properties and Energy Absorption of BCC Lattice Structures with Triply Periodic Minimal Surfaces Fabricated by SLM. Materials, $\quad 11(12), \quad 2411, \quad 2018$. https://doi:10.3390/ma11122411.

[23] O. Al-Ketan and R. K. Abu Al-Rub, Multifunctional mechanical-metamaterials based on triply periodic minimal surface lattices: A review. Advanced

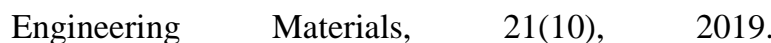
https://doi:10.1002/adem.201900524.

[24] L. Y. Zhu, L. Li, J. P. Shi, Z. A. Li and J. Q. Yang, Mechanical characterization of $3 \mathrm{D}$ printed multimorphology porous Ti6Al4V scaffolds based on triply periodic minimal surface architectures. American journal of translational research, 10(11), 3443-3454, 2018.

[25] N. Yang, Z. Quan, D. Zhang and Y. Tian, Multimorphology transition hybridization CAD design of minimal surface porous structures for use in tissue engineering. Computer-Aided Design, 56, 11-21, 2014. https://doi:10.1016/j.cad.2014.06.006.

[26] C. Körner, A. Bauereiß and E. Attar, Fundamental consolidation mechanisms during selective beam melting of powders. Modelling and Simulation in Materials Science and Engineering, 21(8), 085011, 2013. https://doi:10.1088/0965-0393/21/8/085011.

[27] S. Van Bael, G. Kerckhofs, M. Moesen, G. Pyka, J. Schrooten and J. P. Kruth, Micro-CT-based improvement of geometrical and mechanical controllability of selective laser melted Ti6Al4V porous structures. Materials Science and Engineering: A, 528(24), 7423-7431, 2011. https://doi:10.1016/j.msea.2011.06.04 